\title{
Distribution of a Corticosteroid-binding Protein in Candida and Other Fungal Genera
}

\author{
By DAVID S. LOOSE, ${ }^{1}$ DAVID A. STEVENS, ${ }^{1,3}$ DAVID J. SCHURMAN ${ }^{2}$ \\ and DAVID FELDMAN ${ }^{1}$ * \\ Departments of Medicine ${ }^{1}$ and Orthopedics, ${ }^{2}$ Stanford University School of Medicine, Stanford, \\ CA 94305, U.S.A. \\ ${ }^{3}$ Santa Clara Valley Medical Center and Institute for Medical Research, San Jose, \\ CA 95128, U.S.A.
}

(Received 21 December 1982; revised 31 March 1983)

\begin{abstract}
Using $\left[{ }^{3} \mathrm{H}\right]$ corticosterone as a probe, corticosteroid-binding protein (CBP) was detected in eight out of eight isolates of Candida albicans, of both A and B serotypes. The apparent dissociation constant $\left(K_{\mathrm{d}}\right)$ in the various isolates ranged between 8 and $19 \mathrm{nM}$; the binding capacity varied from 122 to over $2400 \mathrm{fmol}$ ( $\mathrm{mg}$ cytosol protein $)^{-1}$. There was no correlation between the amount or affinity of CBP and isolate virulence for murine hosts. Further analysis revealed demonstrable CBP in six out of six Candida species other than $C$. albicans. One isolate of $C$. tropicalis has been identified which fails to bind $\left[{ }^{3} \mathrm{H}\right]$ corticosterone. Saccharomyces cerevisiae, Neurospora crassa and Paracoccidioides brasiliensis also failed to bind $\left[{ }^{3} \mathrm{H}\right]$ corticosterone. Preliminary attempts were made to determine functions mediated by CBP in Candida, but in vitro growth, phase conversion and glucose oxidation by Candida were unaffected by the addition of a variety of steroid hormones. These data indicate that the presence of CBP in Candida does not correlate with either virulence or serotype. The physiological significance of CBP remains to be determined.
\end{abstract}

\section{INTRODUCTION}

Evidence is accumulating to indicate that fungi utilize message molecules in a fashion analogous to mammalian hormones (Barksdale, 1969; Gooday, 1974; Betz et al., 1981). We recently described the existence of a corticosteroid-binding protein (CBP) in a strain of Candida albicans derived from a clinical isolate and hypothesized that it might represent a primitive hormone receptor (Loose et al., 1981; Loose \& Feldman, 1982). Furthermore, lipid extracts of either the fungal cell pellet or the conditioned growth medium yielded a substance which could competitively displace a $\left[{ }^{3} \mathrm{H}\right]$ corticosterone probe bound to the CBP (Loose et al., 1981). We speculate that this substance represents an endogenous ligand for the binding protein, and is presumed to be hormone-like and released by the fungus into the medium. It is of great interest that not only can mammalian corticosteroids bind to the fungal CBP but the fungal ligand can competitively displace corticosteroids from mammalian glucocorticoid receptors (Loose et al., 1981). The potential for a bidirectional interaction between infecting agent and host suggested to us the possibility that this CBP may have important clinical ramifications. In order to explore this hypothesis further, we examined pathogenic and non-pathogenic fungi to determine the distribution of CBP. In this paper we describe the results of our analysis of CBP in several isolates of C. albicans, species of Candida other than C. albicans, and other selected fungal genera including Saccharomyces, Paracoccidiodes and Neurospora.

Abbreviation: CBP, corticosteroid-binding protein. 


\section{METHODS}

Materials. $\left[1,2,6,7(\mathrm{n})-{ }^{3} \mathrm{H}\right]$ corticosterone $\left(57 \mathrm{Ci} \mathrm{mmol}^{-1}, 2 \cdot 1 \mathrm{TBq} \mathrm{mmol}^{-1}\right)$ was purchased from Amersham and corticosterone from Steraloids (Wilton, N.H., U.S.A.). Sephadex G-50 was obtained from Pharmacia and culture media were purchased from Difco. All other materials were of reagent grade, purchased from Sigma unless specifically noted.

Candida culture and analysis. Strains of $C$. albicans and other Candida species were subcultured on Sabouraud's agar slants and stored at $4{ }^{\circ} \mathrm{C}$. Loopsful of organisms from the slant were used to inoculate $5 \mathrm{ml}$ of Yeast Nitrogen Base broth (YNB) supplemented with $0.5 \%(\mathrm{w} / \mathrm{v})$ glucose. These subcultures were incubated at $35^{\circ} \mathrm{C}$ for $24 \mathrm{~h}$, and the cells were then diluted to an optical density of 0.22 at $600 \mathrm{~nm}$. The diluted cell suspension $(5 \mathrm{ml})$ was used to inoculate $250 \mathrm{ml}$ of YNB (with $0.5 \%$ glucose), which was incubated for $48 \mathrm{~h}$ in a gyratory waterbath (200 r.p.m.) at $35^{\circ} \mathrm{C}$. At this time, all cultures were in plateau phase of growth (identical optical density readings at least $8 \mathrm{~h}$ apart). For the binding studies, cells were harvested by centrifugation, washed in sterile saline, and disrupted by grinding with glass beads as described below. Samples were routinely cultured on blood agar plates to ensure that there were no contaminating organisms.

The Candida strains studied were all derived from clinical isolates and were speciated by standard methods (Silva-Hutner \& Cooper, 1980). Some isolates were a gift from Dr Carlyn Halde, University of California, San Francisco. Serotyping of Candida albicans was done using a slide agglutination technique (Drouhet et al., 1971) with hyperimmune rabbit sera absorbed or unabsorbed with type B cells and specific anti-A factor serum (Stiller $e t$ al., 1982).

Virulence of various laboratory isolates of C. albicans was determined by H. J. Scholer and P. L. Williams. Serial threefold to tenfold dilutions of fungal inocula were injected into six-week-old male CD-1 mice in several experiments, intravenously or intraperitoneally in groups of 5-10 mice. An avirulent strain was defined as one whose $\mathrm{LD}_{50}$ by the intraperitoneal route was $\geq 1 \times 10^{9}$ organisms and whose $\mathrm{LD}_{95}$ by the intravenous route was $\geq 3 \times 10^{8}$ organisms. A virulent strain was defined as one whose LD $_{50}$ by the intraperitoneal route was $\leq 1 \times 10^{8}$ cells and $\mathrm{LD}_{95}$ by the intravenous route was $\leq 1 \times 10^{6}$ organisms. The isolates were grown under identical conditions for the inocula in these studies.

For the growth studies, the strain of yeast used was the clinical isolate of $C$. albicans described previously (Loose et al., 1981; Loose \& Feldman, 1982), here designated stn-1. The growth of $C$. albicans was assessed by a turbidimetric technique described by Galgiani \& Stevens (1976). An inoculum of $1 \times 10^{5}$ cells per ml YNB with $0.5 \%$ glucose was cultured in the presence of the indicated steroids in ethanol or the same volume of ethanol alone (final concentration $0 \cdot 1 \%$ ). Steroid concentrations assayed were $10^{-6}, 10^{-8}$ and $10^{-10} \mathrm{M}$. Growth was assessed spectrophotometrically at $600 \mathrm{~nm}$ two or three times per day, until plateau phase was reached. Ethanol had no effect on the growth of the organism at the concentrations used.

For studies of conversion of $C$. albicans yeast phase to filamentous forms, C. albicans yeast-form (isolate Sh27) cultures were grown in YNB to plateau phase and held for $24 \mathrm{~h}$ at $30^{\circ} \mathrm{C}$. The cells were then washed and resuspended at a density of $5 \times 10^{6} \mathrm{ml}^{-1}$ in RPMI 1640 medium (Gibco, Grand Island, N.Y., U.S.A.). Incubation at $37^{\circ} \mathrm{C}$, led to the initiation of germ tubes, defined as elongated forms larger than the diameter of the parent body. Samples $(50 \mu \mathrm{l})$ were removed at $30 \mathrm{~min}$ intervals, Giemsa-stained slides were prepared (Lehrer, 1970), and 200 cells were counted to enumerate yeast forms and filamentous forms.

For studies of glucose oxidation, C. albicans yeast form (isolate stn-1) was grown as described above for $24 \mathrm{~h}$ in medium containing $10^{-6} \mathrm{M}$-corticosterone, progesterone, dexamethasone or ethanol vehicle. The rate of glucose oxidation over a $1 \mathrm{~h}$ period was determined by measuring the oxidation of $\mathrm{D}-\left[\mathrm{U}-{ }^{14} \mathrm{C}\right] \mathrm{glucose}$ to ${ }^{14} \mathrm{CO}_{2}(\mathrm{Munck} \&$ Zyskowski 1975).

Saccharomyces cerevisiae strain X2180-1B ( $\alpha$ mating type) and strain X2180-1 A (a mating type) were gifts from Dr Seymour Fogel, University of California, Berkeley. Both $\mathbf{a}$ and $\alpha$ haplotypes as well as the diploid $\mathbf{a} / \alpha$ were studied. This organism was routinely grown in YNB broth supplemented with glucose $\left(20 \mathrm{~g}^{-1}\right)$. Organisms were grown for $24 \mathrm{~h}$ in a shaking water-bath at $30^{\circ} \mathrm{C}$ and harvested as described for Candida.

Neurospora crassa strain bd-csp was a gift from Dr Dow Woodward, Stanford University. The spores grown from these cells as well as the mycelial form of this organism were studied. Spores were harvested after $9 \mathrm{~d}$ from a culture of $N$. crassa in Vogel's salts with $1.5 \%$ sucrose and $1.5 \%$ agar. Spores were washed with distilled water, collected by filtration and broken by agitation with glass beads. The mycelium form of this organism was grown in the same medium, except the agar was omitted. The mycelium was allowed to grow for $3 \mathrm{~d}$ before harvesting.

Paracoccidioides brasiliensis, a recent clinical isolate from Colombia, was maintained in the yeast form on agar. Cells were grown in modified McVeigh Morton medium on a gyratory shaker at $35^{\circ} \mathrm{C}$. Yeasts were harvested after 2 weeks. Contamination of cultures was excluded by sub-culture on to blood agar plates before harvesting.

Assay of the fungal binding protein. Details of the method for assay of $\left[{ }^{3} \mathrm{H}\right]$ corticosterone binding to CBP have been published previously (Loose \& Feldman, 1982). In brief, cells were harvested, washed with saline and suspended in a homogenizing medium containing $250 \mathrm{~mm}$-sucrose, $10 \mathrm{~mm}$-Tris, $10 \mathrm{~mm}$-sodium molybdate, $1.5 \mathrm{~mm}$-EDTA and $12 \mathrm{~mm}$-monothioglycerol, $\mathrm{pH} 7 \cdot 8$. Cells were disrupted by vigorous agitation with glass beads 
on a vortex mixer. The lysate was centrifuged at $204000 \mathrm{~g}$ for $30 \mathrm{~min}$ to prepare a cytosol fraction. Binding studies were performed with this cytosol preparation using conditions previously shown to provide peak steady-state binding. $\left[{ }^{3} \mathrm{H}\right]$ Corticosterone was incubated with fungal cytosol for $3 \mathrm{~h}$ at $0^{\circ} \mathrm{C}$. Bound hormone was separated from free hormone using G-50 Sephadex minicolumns which were made just prior to the experiment and matched for flow rate. In all experiments non-specific binding was assessed by addition of a 250 -fold molar excess of radioinert corticosterone to parallel incubations of identical samples. Specific binding was calculated by subtracting nonspecific binding from total binding. In some cases, cytosol was incubated with increasing concentrations of $\left[{ }^{3} \mathrm{H}\right]-$ corticosterone and the results analysed by the method of Scatchard (1949). This analysis yielded the apparent dissociation constant $\left(K_{\mathrm{d}}\right)$ and the $N_{\max }$ or maximum binding capacity. If protein concentration was low $\left(<0.25 \mathrm{mg} \mathrm{m}^{-1}\right.$, final concentration) due to difficulties in cell growth or in disruption of the cells, single point analysis of $\left[{ }^{3} \mathrm{H}\right]$ corticosterone binding at $26 \mathrm{nM}$ was performed. This concentration should saturate the binding protein, but some underestimate of total binding capacity is inevitable using this technique, especially when attempting to measure a binding site with a low affinity.

\section{RESULTS}

\section{Distribution of CBP in Candida species}

The distribution of CBP was examined in a series of $C$. albicans isolates including both A and $B$ serotypes. The isolates were assessed for virulence in concurrent in vivo experiments in mice (Table 1). By the criteria described in Methods, two isolates were of low virulence and six were of high virulence. CBP was present in all isolates. The apparent dissociation constant $\left(K_{\mathrm{d}}\right)$ or affinity of $\left[{ }^{3} \mathrm{H}\right]$ corticosterone for CBP varied between 8 and $19 \mathrm{nM}$. This value is similar to the $K_{\mathrm{d}}$ found in mammalian steroid-binding systems. On the other hand, the maximal binding capacity varied over a very wide range: 122 to $2414 \mathrm{fmol}(\mathrm{mg} \text { protein })^{-1}$.

We then determined whether CBP was limited to C. albicans or whether it was distributed in multiple Candida species. At present this genus contains 81 member species (VanUden \& Buckley, 1970) of which about $30 \%$ are associated with man (Hurley, 1980). The results of the limited survey we performed are summarized in Table 2. Of the six species tested (including $C$. stellatoidea, which some yeast taxonomists currently hold to be synonymous with $C$. albicans), all possessed CBP but in quite variable amounts. The range of measured dissociation constants in this series was 6-38 nM. Candida guilliermondii had the highest level of binding capacity of the species examined, in excess of $6500 \mathrm{fmol} \mathrm{mg}^{-1}$. The apparent dissociation constant in this species was $38 \mathrm{~nm}$. One strain of $C$. tropicalis, listed as djs- 1 failed to bind $\left[{ }^{3} \mathrm{H}\right]$ corticosterone. This strain has been examined under three different conditions of growth: as a cell suspension in two different liquid media (YNB and Brain Heart Infusion), and on agar, and has never displayed any specific binding. Careful biochemical examination of these cells has confirmed their identification as C. tropicalis (Silva-Hutner \& Cooper, 1980). The other strain of $C$. tropicalis thus far studied (das-1) possessed a $\left[{ }^{3} \mathrm{H}\right]$ corticosterone-binding protein, although with a relatively low binding capacity. In some experiments the two $C$. tropicalis isolates were cultured under identical conditions on the same day, and the binding studies performed concurrently. These studies confirmed the presence of CBP in one strain and its absence in the other.

To better illustrate the range of the binding parameters found, Scatchard plot analyses of CBP from three of these species are compared with that for the original $C$. albicans strain (stn-1) previously reported (Loose et al., 1981) and the data are presented in Fig. 1. These four species represent the upper and lower limits of the observed binding capacities and affinities. In all cases where specific binding has been detected, the Scatchard plots appear linear suggesting a single class of binding sites. The clearly different slope of the line calculated from the $C$. guilliermondii data shows no indication of the presence of a higher affinity component. The affinities varied by about sixfold (excluding the djs-1 strain of $C$. tropicalis, which had no binding).

In our initial description of the C. albicans CBP, yeasts were grown for $24 \mathrm{~h}$ on agar (Loose $e t$ al., 1981). Binding parameters observed under these conditions were a $K_{\mathrm{d}}$ of $7 \cdot 2 \pm 0.5 \mathrm{~nm}$ with a binding capacity of $732 \pm 73 \mathrm{fmol} \mathrm{mg}^{-1}$. When the same strain is grown in YNB liquid medium, there is a reduction in the binding capacity $\left(225 \mathrm{fmol} \mathrm{mg}^{-1}\right)$ and no significant change in affinity (6.5 nM) (Fig. 1). 
Table 1. $\left[{ }^{3} \mathrm{H}\right]$ Corticosterone binding in various isolates of Candida albicans

Binding parameters were determined by Scatchard analysis. In those strains where the protein yield was low, binding capacity was estimated using a single point analysis at $26 \mathrm{nM}-\left[{ }^{3} \mathrm{H}\right]$ corticosterone. In those cases a $K_{\mathrm{d}}$ measurement was not determined (ND). Virulence was assessed by intravenous and intraperitoneal injection of the fungus into mice as described in Methods.

\begin{tabular}{|c|c|c|c|}
\hline Isolate & $\begin{array}{c}K_{\mathrm{d}} \\
(\mathrm{nM})\end{array}$ & $\begin{array}{c}N_{\max } \\
\left.[\text { fmol (mg protein })^{-1}\right]\end{array}$ & Virulence \\
\hline \multicolumn{4}{|c|}{ Serotype A } \\
\hline Sh 8 & 12 & 918 & Low \\
\hline Sh 27 & 15 & 1360 & Low \\
\hline H 12 & 19 & 1255 & High \\
\hline $140 / 1$ & 8 & 1993 & High \\
\hline $610^{\prime}$ & ND & 2414 & High \\
\hline 603 & ND & 702 & High \\
\hline \multicolumn{4}{|l|}{ Serotype B } \\
\hline Sh 13 & 17 & 179 & High \\
\hline 366 & ND & 122 & High \\
\hline
\end{tabular}

\section{Table 2. $\left[{ }^{3} \mathrm{H}\right]$ Corticosterone binding in various species of the genus Candida}

Binding parameters were determined by Scatchard analysis. In species where the protein yield was low, binding capacity was estimated using a single point analysis at $26 \mathrm{nM}-\left[{ }^{3} \mathrm{H}\right]$ corticosterone. In these cases a $K_{\mathrm{d}}$ measurement was not determined (ND). Negative binding means that total binding was indistinguishable from non-specific binding.

\begin{tabular}{lcc}
\multicolumn{1}{c}{ Species } & $\begin{array}{c}K_{\mathrm{d}} \\
(\mathrm{nM})\end{array}$ & $\begin{array}{c}\text { Binding capacity } \\
\text { [fmol (mg protein) }\end{array}$ \\
C. . guilliermondii & 38 & 6530 \\
C. krusei & ND & 80 \\
C. pseudotropicalis & 15 & 285 \\
C. parapsilosis & ND & 4479 \\
C. stellatoidea & 6 & 345 \\
C. tropicalis strain das-1 & 15 & 79 \\
C. tropicalis strain djs-1 & Negative & Negative
\end{tabular}

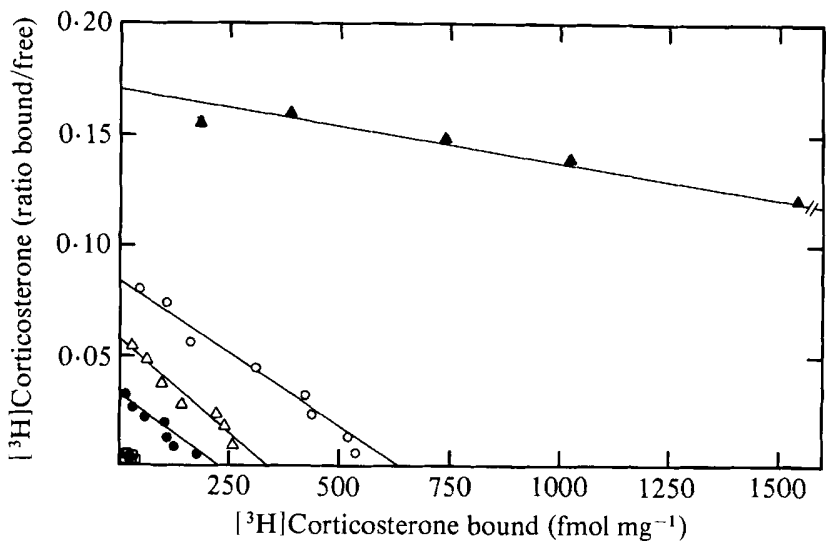

Fig. 1. Scatchard analysis of specific $\left[{ }^{3} \mathrm{H}\right]$ corticosterone binding in four species of Candida. The organisms depicted here demonstrate the range of binding capacities and affinities encountered in this study. $\mathbf{A}$, C. guilliermondii; $\bigcirc, C$. albicans stn-1 grown on agar;,$C$. albicans stn-1 grown in YNB broth; $\triangle, C$. stellatoidea; $\square, C$. tropicalis strain djs-1. 


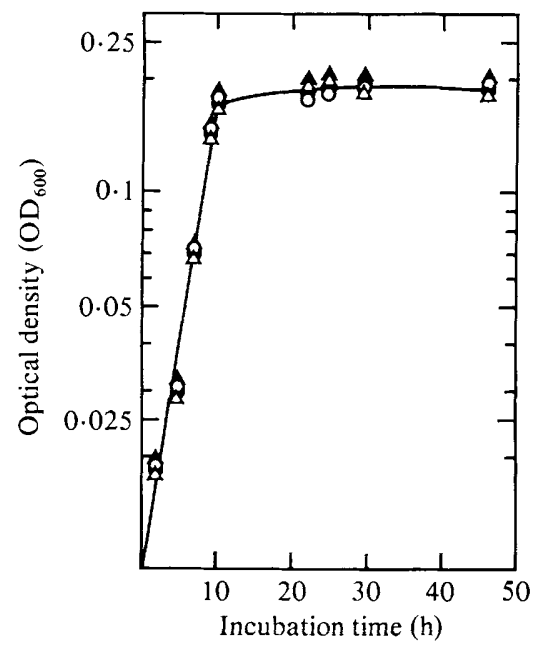

Fig. 2. Absence of an effect of various mammalian steroids on the growth pattern of $C$. albicans. Candida albicans stn-1 was grown in YNB broth with $0.5 \%$ glucose containing $10^{-6} \mathrm{M}$ of the indicated steroid hormones and optical density was monitored by a spectrophotometer at $600 \mathrm{~nm}$. Concentrations of $10^{-8}$ and $10^{-10} \mathrm{M}$ steroid also had no effect. $\bigcirc$, Control ; $\triangle$, dexamethasone; $O$, corticosterone; $\Delta$, progesterone.

\section{Distribution of CBP in other fungi}

Several forms of Saccharomyces cerevisiae were assessed for CBP. The two haplotypes of this organism, a cells and $\alpha$ cells, displayed no $\left[{ }^{3} \mathrm{H}\right]$ corticosterone binding (i.e. there was no difference between total and non-specific binding). The $\mathbf{a} / \alpha$ diploid form also failed to exhibit specific binding of the radioprobe. Both the spores and the mycelial form of Neurospora crassa were examined for CBP and neither displayed specific binding. In some experiments with this

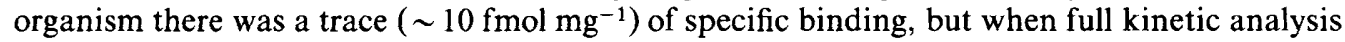
was performed, no saturable binding could be demonstrated. The third genus we tested was Paracoccidioides. The species examined was $P$. brasiliensis, a pathogen endemic in Latin America (Pena, 1967). No $\left[{ }^{3} \mathrm{H}\right]$ corticosterone binding was evident in this organism.

\section{Lack of effect of corticosteroids on C. albicans cell growth, metabolism and phase conversion}

We hypothesize that CBP represents a primitive hormone receptor which binds an endogenous message molecule. If this is the case, it is not yet clear what aspects of fungal physiology are regulated by CBP. We attempted to determine whether corticosteroids active in mammalian systems and which bind to CBP (Loose et al., 1981; Loose \& Feldman, 1982) would modulate the basic processes of fungal cell growth. Candida albicans strain stn-1 was cultured in the presence of three different steroids (corticosterone and progesterone, two potent binders, and dexamethasone, a weak binder to CBP) and the results were compared to controls. No effect on cell growth was observed with concentrations of $1 \times 10^{-6} \mathrm{M}$ (Fig. 2). Three points can be made from these data: (1) the steroids tested do not cause a change in the time to the onset of exponential growth, (2) there was no change in the rate of exponential growth, implying no change in the length of the cell cycle, and (3) there was no change in the cell concentration at plateau phase after treatment. No effects were detected with the two lower steroid concentrations $\left(1 \times 10^{-8}\right.$ and $\left.1 \times 10^{-10} \mathrm{M}\right)$.

Corticoid hormones might, in the host, affect conversion of the yeast form of C. albicans, the form found during colonization, to the elongated hyphal or pseudohyphal form. The latter form has been associated with tissue invasion (Mariat, 1964), and host resistance to C. albicans invasion is impaired by pharmacological doses of corticosteroids (Frenkel, 1962). We investigated this possibility by testing whether high corticosterone concentrations would affect the rate 
of conversion in vitro. No steroid effect on phase conversion was detected. We found that of $10^{-6} \mathrm{M}$-corticosterone-treated yeast cultures, $0 \%, 34 \%$, and $77 \%$ converted to filamentous forms during 30, 45 and $60 \mathrm{~min}$ incubation, respectively. This was indistinguishable from controls $(2 \%, 33 \%$ and $76 \%$, respectively). Two other experiments showed similar results.

The ability of the same mammalian steroids to alter $\left[{ }^{14} \mathrm{C}\right]$ glucose oxidation to ${ }^{14} \mathrm{CO}_{2}$ was also examined in $C$. albicans stn-1. After 4 h of steroid treatment no effects were detected.

\section{DISCUSSION}

We have postulated that Candida CBP might represent a primitive hormone-receptor system (Loose et al., 1981; Loose \& Feldman, 1982). Since the protein has a high affinity for mammalian corticosteroids, circulating host hormones could achieve substantial occupancy of the fungal binding site, possibly altering Candida pathogenicity or other properties. The current study was undertaken to determine the distribution of this binding protein in several C. albicans isolates, other Candida species, and other fungi, and to attempt to determine a function of the hypothesized fungal hormone-receptor system.

Of four fungal genera thus far examined, only Candida possesses CBP. The binding protein was found in Candida species known to be pathogenic for man and in others which are rarely pathogenic for man, and then only in an opportunistic setting. No specific binding was detected in Sacch. cerevisiae or N. crassa, two non-pathogenic fungi. Paracoccidioides brasiliensis was studied to determine if CBP is present in other yeasts which are pathogenic in man. Since $P$. brasiliensis also fails to bind $\left[{ }^{3} \mathrm{H}\right]$ corticosterone, no such association is apparent. These findings do not imply that these organisms are devoid of any steroid-binding proteins; in fact both Sacch. cerevisiae (Feldman et al., 1982) and P. brasiliensis (Feldman et al., 1983) possess binding proteins which exhibit high affinity for oestradiol. However, CBP does not appear to be present in all fungal genera; thus far, the protein seems to be specific for Candida.

The examination of various Candida species revealed some interesting results. All six species tested were found to possess $\mathrm{CBP}$, but the binding capacity varied markedly (80$\left.6500 \mathrm{fmol} \mathrm{mg^{-1 }}\right)$. The binding affinity for $\left[{ }^{3} \mathrm{H}\right]$ corticosterone varied to a lesser degree $(6-38 \mathrm{nM})$. One strain of $C$. tropicalis failed to bind $\left[{ }^{3} \mathrm{H}\right]$ corticosterone. This strain will provide an ideal control in further studies of CBP-positive strains. The isolates of C. albicans tested were assessed for virulence by intraperitoneal and intravenous injection into mice. No correlation was found between virulence of $C$. albicans in vivo and the binding capacity or affinity of CBP. These data suggest that CBP may be specific to Candida, but that it is found in many species and strains within the genus and is unrelated to virulence.

Our hypothesis that CBP represents a receptor system in Candida requires that ligand binding should initiate a function in the yeast. We have not yet isolated the fungal endogenous ligand in pure form or in sufficient quantity to test it for activity. However, a corollary of our hypothesis is that mammalian hormones, by virtue of their ability to bind to CBP, might also influence Candida functions. We have been able to demonstrate that $\left[{ }^{3} \mathrm{H}\right]$ corticosterone added to the medium can enter intact yeast and specifically occupy CBP sites (data not shown). In the three functions tested thus far no steroid activity was discernible. The lack of an action in these three assays does not, of course, exclude the possibility that mammalian hormones may regulate other functions in Candida.

In summary, we have demonstrated the existence of a specific, high affinity corticosteroidbinding protein in several Candida species. These data indicate that the presence of CBP does not correlate with either the virulence of the organism or serotype. Also, the mammalian corticosteroids which bind to the fungal CBP apparently do not simply modify the in vitro growth of the organism. The functions mediated by this protein remain to be determined and may ultimately require investigation employing the endogenous ligand extracted from Candida. Further studies are in progress to elucidate both the role of this protein in Candida and its possible interaction with circulating steroid hormones in the mammalian host.

The authors are grateful to Price Stover for his assistance in carrying out many of these studies. 


\section{REFERENCES}

BARKSDALE, A. W. (1969). Sexual hormones of Achlya and other fungi. Science 166, 831-837.

Betz, R., Manney, T. R. \& Duntze, W. (1981). Hormonal control of gametogenesis in the yeast Saccharomyces cerevisiae. Gamete Research 4, 571584.

Drouhet, E., Balota, V., Borderon, J. C. \& RousSET, J. J. (1971). Recherches sur les serotypes A et $\mathrm{B}$ de C. albicans. Bulletin de la Société francaise de mycologie medicale 19, 30-31.

Feldman, D., Do, Y., Burshell, A., Stathis, P. \& LOOSE, D. (1982). An estrogen binding protein and endogenous ligand in the yeast Saccharomyces cerevisiae: a possible steroid-receptor system. Science 218, 297-298.

Feldman, D., Loose, D., Stover, P., Restrepo, A. \& Stevens, D. (1983). A receptor-like estrogen binding protein in Paracoccidiodes brasilensis $(\mathrm{Pb})$ : possible basis for lower infection rate in women than men. Clinical Research 31, 470A.

FrenKel, J. K. (1962). Role of corticosteroids as predisposing factors in fungal diseases. Laboratory Investigation 11, 1192-1208.

Galgiani, J. N. \& Stevens, D. A. (1976). Antimicrobial susceptibility testing of yeasts: a turbidimetric technique independent of inoculum size. Antimicrobial Agents and Chemotherapy 10, 721726.

Gooday, G. W. (1974). Fungal sex hormones. Annual Review of Biochemistry 43, 35-49.

Hurley, R. (1980). The pathogenic Candida species and diseases caused by Candida in man. In Biology and Activities of Yeasts, pp. 231-248. Edited by F. A. Skinner, S. M. Passmore \& R. R. Davenport. New York: Academic Press.

LEHRER, R. I. (1970). Measurement of candidacidal activity of specific leukocyte types in mixed cell populations. I. Normal, myeloperoxidase-deficient, and chronic granulomatous disease neutrophils. Infection and Immunity 2, 42-47.

Loose, D. S. \& Feldman, D. (1982). Characterization of a unique corticosterone-binding protein in Candida albicans. Journal of Biological Chemistry 257, 4925-4930.

Loose, D. S., Schurman, D. J. \& Feldman, D. (1981). A corticosteroid binding protein and endogenous ligand in C. albicans indicating a possible steroidreceptor system. Nature, London 293, 477-479.

MARIAT, F. (1964). Saprophytic and parasitic morphology of pathogenic fungi. In Microbial Behaviour In Vivo and In Vitro, pp. 85-111. Edited by H. Smith \& J. Taylor. Cambridge: University Press.

Munck, A. \& Zyskowski, L. (1975). Methods for assessing kinetics of hormone effects on energy and transport mechanisms in cells in suspension. Methods in Enzymology 36A, 429-433.

Pena, C. (1967). Deep mycotic infections in Colombia: a clinicopathologic study of 162 cases. American Journal of Clinical Pathology 47, 505-520.

SCATCHARD, G. (1949). The attractions of proteins for small molecules and ions. Annals of the New York Academy of Sciences 51, 660-672.

Silva-Hutner, M. \& CoOPER, B. H. (1980). Yeasts of medical importance. In Manual of Clinical Microbiology, 3rd edn, pp. 562-576. Edited by E. H. Lennette. Washington D.C.: American Society for Microbiology.

Stiller, R. L., Bennett, J. E., Scholer, H. J., Wall, M., PolaK, A. \& Stevens, D. A. (1982). Susceptibility to 5-fluorocytosine and prevalence of serotype in 402 Candida albicans isolates from the United States. Antimicrobial Agents and Chemotherapy 22, 482-487.

VANUden, N. \& BUCKLeY, H. (1970). Candida Berkhout. In The Yeasts-A Taxonomic Study, 2nd edn, pp. 893-1087. Edited by J. Lodder. Amsterdam: North Holland. 